\title{
The Financial Risk and Its Control of E-Commerce Enterprise Based on the Perspective of Integrated Supply Chain
}

\author{
Li Zhen ${ }^{1}$ \\ ${ }^{1}$ Bohai Ship Building Vocational College, Xingcheng, Liaoning, 125105 \\ 346591653@163.com
}

KEYWORDS: E-Commerce Enterprise; Integrated Supply Chain; Financial Risk

\begin{abstract}
With the growth spurt of total number of Internet users, the scale of e-commerce transactions is increasing and is also increasingly showing its unique advantage. The e-commerce has become the new trading patterns which many companies chasing. This paper analyzes the new requirements of enterprise financial management in e-business environment, combined with e-commerce features proposed the construction of a network-based e-commerce system and financial security system; the establishment of financial risk early warning mechanism; reconstruction of organizational structure, optimize business processes ; innovative financial management, promote the fine countermeasures to promote the sustainable development for new enterprises.
\end{abstract}

\section{Introduction}

In recent years, the rapid development of e-commerce, according to data provided by the Ministry of Commerce show that the scale of e-commerce transactions in 2012 reached 8.1 trillion $\mathrm{RMB}$ in 2015 is projected to reach 18 trillion RMB. With the increasing scale of e-commerce transactions, many enterprises have become the global network of supply chain node, corporate purchase payments, sales of receivables, cargo insurance, and many other economic and business activities can be carried out through the network, so that their trading patterns and settlement have undergone a major change, which provides a broad space and possibly corporate financial management, but also for corporate financial management with new challenges and requirements. Therefore, the study of enterprise financial management countermeasure under electronic commerce environment is promoting the development of new enterprises urgent requirement.

\section{The New E-commerce Environment Requirement for Enterprise Financial Management}

A. E-commerce Requires Enterprises to Strengthen Financial Risk Management

Enterprise Financial risk refers to business opportunities in the financial activities, due to the uncertainties resulting from business losses and possible, including funding risk, investment risk, operational risk capital, capital recovery risk and income distribution risk. In the traditional business environment, enterprise financial management is the real sport activities in order to change the characteristics of the material management, and e-commerce environment, companies sometimes do not show specific physical form, such as e-commerce transactions from bilateral trade negotiations, contract to the purchase price paid by the network and so can be completed quickly so that the 
entire transaction remote, real-time and virtualization, these changes make financial forecasting, planning, decision making and other work time is shortened, corporate financial management timeliness, adaptability elastic and put forward higher requirements, but also the enterprise has brought new credit risk network, network security, network operations and information processing, but also increase the difficulty of financial risk management. And this requires companies to re-identify the content and forms of e-commerce environment of different business processes risks, financial risks facing assess, establish an effective risk warning mechanism, in order to avoid financial risk.

\section{B. E-commerce Requires Companies to Change the Financial Management}

In the traditional business environment, due to lack of technical means to support centralized financial management, and the development of enterprises by geographical constraints, resulting in many branches of enterprises, especially large corporate enterprises have to adopt decentralized financial management model that is easy resulting in inadequate supervision of subsidiary bodies, feedback lag and low work efficiency. In the e-commerce environment, companies purchase payments, sales of receivables, cargo insurance and other business activities can be completed in the shortest possible time, in space and time from the business greatly reduced; the financial system through the introduction of advanced technologies such as network management tools, companies can immediate and effective direct access to economic and business activity data to achieve unified management of data and information sharing; and corporate finance executives can implement centralized accounting treatment for all branches, centralized allocation of funds; corporate management can keep track of the various branches of production , inventory, sales and cash flow, the effective oversight of the business and the customers and suppliers of capital flow, you can also implement remote control, on-line management of all branches of the financial management capability extends to every node, so as to centralized financial management to create good conditions. Therefore, enterprises must establish e-commerce environment to adapt centralized financial management, financial management of the environment to adapt to changing requirements.

\section{Management of the e-commerce business environment}

\section{A. Build a Network of Financial Systems and E-commerce-based Security System}

E-commerce is not only needed for the Internet material basis, but also we need to have a powerful network of financial software to support its operations. We can say that the network is the basis of financial e-business applications and it is also an important part of e-commerce. Internet-based financial network technology, with support functions of electronic documents and electronic money, changed the way of access to and use of financial information, the corresponding financial data also changed the traditional forms of paper-based and disk-based data, and the data is converted to page can effectively resolve network-related financial issues in e-commerce environment to run the process. To meet the e-commerce environment enterprise financial management requirements, enterprises should establish a network of financial systems in line with its own characteristics, including: First, demand analysis. From economic feasibility, technical feasibility and environmental feasibility analysis, Enterprises determine other aspects of the financial system require a network to complete the work, to achieve what goals and requirements. Followed by the software evaluation and selection, Enterprises should respect the applicability of the software, interoperability, scalability, stability, service and integration with e-commerce systems, etc. for a variety of network analysis and evaluation of financial software and make carefully 
chosen to ensure that the software functions are fully and effectively support the enterprise's production operations. The third is the specific design and implementation of programs. Enterprise network architecture to choose the applicable net financial structure, server operating systems, workstations, operating systems and database systems, software and hardware platform based on software provided by software developers or distributors installation, parameter setting, initialization data, personnel training other services; after completion of the system, but also for testing a variety of functions, comprehensive testing its operation, to ensure network security and stable operation of the financial system.

Internet network by relying on the financial system using an open CP / IP protocol, and e-commerce also involves a large number of electronic orders, electronic money and so on, so that the network of financial facing more security threats. Meanwhile, the enterprises to establish a network of financial systems, financial management and business management of the enterprise is almost entirely dependent on the network system, if the internal control is lax or negligent in monitoring and maintenance, it will seriously affect the overall operation of the enterprise network system and even lead to paralysis, especially Business confidential financial data demanding enterprise, if the information is damaged or compromised, enterprises will result in incalculable losses, we can say the most prominent problems facing the financial network is security issues. Therefore, enterprises should build tight network of financial security system, in order to eliminate safety hazards. Companies on the one hand to establish a strict system of internal accounting controls financial network, set up to personnel management from the organization, from operations to the documentation management system, environmental control system to prevent and eliminate computer viruses and the like from should establish a set of effective measures to ensure the security of the network in the institutional financial system; on the other hand to prevent foreign invasion by firewalls, network intrusion detection systems, fault detection and vulnerability scanning technology.

\section{B. Establish Effective Financial Risk Early Warning Mechanism}

Dynamic internal controls from the enterprise risk awareness and management, enterprise risk management and internal control combine to ensure that risk management mechanisms are effectively implemented. In the e-commerce model, the company's control environment, risk assessment, control activities, information and communication

Supervision have undergone major changes; to implement effective risk management, corporate sources of risk should be based on the characteristics of its e-commerce, establish a sound internal control system and the enterprise. For this reason, enterprises should actively create a suitable internal and external control environment, establish systems to install, update, expand, system backup of the contents of the maintenance control system, investigation and analysis of the mode of operation on the upstream and downstream businesses, enabling enterprises to electronic Business content management, and e-commerce activities in the role of the law of supply chain management standards for business processes and internal restructuring adjustments; corporate finance and operational staff to focus on business processes that may exist

In trading risk, credit risk and safety risks are identified and a comprehensive assessment and develop appropriate response measures to control the risk to a minimum; to use information technology to strengthen control activities, establish business processes and match internal control system, a clear mandate and responsibilities of each position, to ensure user authorization, authentication, system maintenance and application personnel and other incompatible positions authorization approval phase separation and control; to optimize information transmission and processing procedures, the establishment of clear communication of information mechanisms to 
ensure information is timely feedback to the relevant departments and personnel to improve the timeliness and effectiveness of information communication; in the internal control system development to embed business processes, allowing operators together with daily supervision, the supervision afterwards, when Point oversight into advance the prevention, control and full supervision things, to ensure the effectiveness of internal oversight.

\section{Conclusion}

With the rapid development of e-commerce, corporate financial management have become increasingly demanding, business managers should build a network of financial system, establish a risk early warning mechanism, optimize business processes and innovative financial management model and take measures to provide better services for business development.

\section{REFERENCE:}

[1] Li-Zhi M. On the Choice of E-commerce Environment of Financial Management Information System Construction [J]. Chinese Securities and Futures, 2013, (6).

[2] Li Mei. Reflections on Establishing Financial Risk Early Warning Mechanism[J]. Western Finance and Accounting, 2009, (12).

[3] Yu-Yao M. Risk Factors for Risk Management[J]. Chinese E-commerce, 2012, (10).

[4] Jia W. Financial Management [J]. Economic Perspective, 2012, (6). 